\title{
GRAND FINALE DA OBRA DE OLIVEIRA VIANNA EM NOSSA CONSTITUIÇÃO?
}

\section{GRAND FINALE OF THE WORK OF OLIVEIRA VIANNA IN OUR CONSTITUTION?}

\author{
MARCELO TOLOMEI TEIXEIRA \\ Doutorando em Direitos e Garantias Fundamentais da Faculdade de Direito de Vitória (FDV). \\ Juiz (Federal) do Trabalho - Tribunal Regional do Trabalho da $17^{a}$ Região. Vitória, ES, Brasil. \\ tolomei@trt17.gov.br
}

DAURY CeSAR FABRIZ

Doutor em Direito pela Universidade Federal de Minas Gerais (UFMG). Professor na Universidade Federal do Espírito Santo (UFES) e na Faculdade de Direito de Vitória (FDV). Vitória, ES, Brasil.

daury@terra.com.br

\begin{abstract}
RESUMO
0 presente artigo objetiva investigar a interpretação de Oliveira Vianna acerca do fenômeno que desencadeou o desenvolvimento da nova classe urbana trabalhadora, bem como os seus conflitos. Por meio da análise de Vianna sobre sindicato e poder normativo da Justiça do Trabalho, pretende-se descrever a proposta do autor sobre este problema, a partir das origens de sua teoria e a maneira que essas instituições estiveram presentes em nossas Constituições, inclusive como reais possibilidades de mudanças. Como metodologia, adotou-se a dialética para confrontar as obras do autor, as quais se pautam no solidarismo, corporativismo e nas atualizações do realismo jurídico americano, com as obras de seus respectivos críticos. As principais conclusões apontam que a presença do modelo de Vianna nas Constituições reduziu as possibilidades da classe trabalhadora enquanto sujeito histórico, por se tratar de uma proposta, que privilegiou o legislado e os sindicatos não representativos.
\end{abstract}

Palavras-chave: corporativismo; Estado autoritário; Justiça do Trabalho; poder normativo; sindicato único.

\begin{abstract}
This article aims to investigate the interpretation of Oliveira Vianna about the phenomenon that triggered the development of the new urban working class, as well as their conflicts. By Vianna's analysis of labor union and normative power of the Labor Court, it intends to describe the proposal of the author about this issue, from the origins of his theory and the way in which these institutions were present in our Constitutions, including as real possibilities of change. It adopted the dialectic method to confront the author's works, which are guided in solidarism, corporatism and the American legal realism updates, with the works of their critics. The main findings indicate that the presence of Vianna's model in the Constitutions reduced the possibilities of the working class as a historical subject, because it is a proposal which favored the legislated and unrepresentative labor unions.
\end{abstract}

Keywords: corporatism; authoritarian state; Labor justice; normative power; single labor union. 


\section{SUMÁRIO}

INTRODUÇÃO; 1 AS TEORIAS PRINCIPAIS; 2 O PROJETO DE JUSTIÇA DO TRABALHO E SUA TRADIÇÃO EM NOSSAS CONSTITUIÇÕES; 3 O PROJETO DE SINDICATO E SUA TRADIÇÃO EM NOSSAS CONSTITUIÇÕES; CONCLUSÃO; REFERÊNCIAS.

\section{INTRODUÇÃO}

A obra do Oliveira Vianna é intensa: sociólogo, antropólogo, preocupado com a psicologia social das massas e jurista, seu legado merecerá sempre intensa atenção de quem deseje interpretar o Brasil. Homem marcado pela geração de trinta e ladeado pela figura lendária de Getúlio Vargas, foi também, longe de atividades meramente acadêmicas, de forte atuação política, já que teve influência marcante em nossa legislação social e na criação da Justiça do Trabalho, apontado até como seu criador. Exerceu as funções de: Diretor do Fomento Agrícola, Membro do Conselho Consultivo do Estado do Rio de Janeiro, Consultor Jurídico do Ministério do Trabalho e Ministro do Tribunal de Contas da União. Combateu o bom combate? Eis controvérsia interessante como é desenvolvido ao longo desse artigo.

Não há dúvidas de que sua atuação na ditadura do Estado Novo e sua aposta em um Estado autoritário e centralizador gerou e gera imensas controvérsias, mas não se pode deixar de reconhecer sua coerência em suas acepções, pois mesmo quando Vargas, após a Constituição de 1946, assume os ares de adepto à democracia e retorna ao poder pelo sufrágio universal, Vianna é cético e continua a apostar na necessidade do referido modelo de Estado".

Instituições básicas para a democracia, como "sufrágio universal", "representatividade", "federalismo" e "parlamento" são para Vianna instituições importadas e, para nossa gente, o que interessava eram os direitos à educação, ao trabalho. A respeito das garantias individuais, tão renegadas ou mesmo inexistentes em nossa democracia real; neutralizar a ação nociva do espírito de clã do nosso organismo político-administrativo, ou quando não seja possível, neutralizá-las, reduzir ao mínimo a sua influência e nocividade era sua bandeira. Com certeza, suas preocupações parecem modernas ainda hoje, quando a real cidadania é tão renegada. De fato, do que adianta depositar o voto nas urnas, de forma universal, quando o povo tem seus direitos básicos não reconhecidos na prática? Questionamento que nos parece atualíssimo.

${ }^{1}$ BRESCIANI, Maria Stela Martins. O charme da ciência e a sedução da objetividade. 1. ed. São Paulo: UNESP, 2005. p. 134. 
ISSN 1981-3694

(DOI): $10.5902 / 1981369423065$

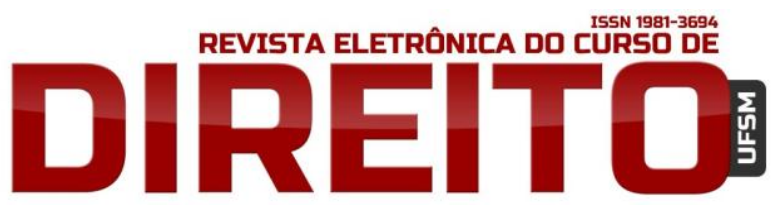

GRAND FINALE DA OBRA DE OLIVEIRA VIANNA EM NOSSA CONSTITUIÇÃO?

MARCELO TOLOMEI TEIXEIRA DAURY CESAR FABRIZ

Evidentemente, a solução que encontra a de um Estado autoritário, provedor das carências, uma democracia instrumental, também pode dar margens as mais variadas críticas. Enfim, é o enigma da política em Vianna, com solução das mais ortodoxas, e em voga nos anos trinta e quarenta ante a proliferação de estados autoritários (fascismo, nazismo, stalinismo).

Dos muitos ângulos de sua obra, interessa ao presente trabalho a arquitetura de sua legislação social, suas origens e seus críticos. Sua perspectiva de paz social, numa área tão conflituosa que é a das relações do trabalho, seu credo no corporativismo, que será analisado. Daí o problema que se coloca para esse artigo é o seguinte: qual é exatamente a solução de Vianna para esse problema? Quais as origens de sua teoria? E como que isso permeou na tradição das constituições brasileiras e as possibilidades reais de mudanças sempre inconclusas?

A teoria de base terão suas próprias obras, em especial, as que tratam das questões trabalhistas: "Instituições Políticas Brasileiras", "Problemas de Política Brasileira" e "Problemas de Direito Sindical". Como leitura de apoio, dos muitos estudiosos da obra de Vianna, escolhe-se principalmente: "Oliveira Vianna e o Estado Corporativo" de Evaldo Amaro Vieira e o "O charme da ciência e a sedução da objetividade" de Maria Stela Besciani. No campo jurídico, utilizam-se três juristas que parece de grande valia para os objetivos do artigo: Evaristo de Moraes Filho, que criticou em muitos pontos a geração "varguista" no campo da legislação trabalhista, Arnaldo Sussekind que foi um partícipe na elaboração da CLT e Maurício Godinho Delgado que representa uma das vozes atuais mais importantes do Direito do Trabalho.

Nosso método será o dialético, no sentido do diálogo e confronto de suas obras, notadamente as acima detalhadas, e a busca do todo de seu impressionante projeto de legislação social, baseada em seu credo, repetimos, pelo solidarismo, corporativismo e nas novidades do realismo jurídico americano, tudo em contraste com seus críticos.

O objetivo então será analisar como Vianna interpretou o fenômeno novo do desenvolvimento da classe urbana trabalhadora e seus conflitos, e como, já dissemos, na qualidade de homem prático, fugindo do liberalismo e do comunismo, socialismo ou anarquismo, encontrou um projeto para as relações trabalhistas que ainda repercutem em dois pontos fundamentais: a ideia da Justiça do Trabalho como árbitro, dando a palavra final aos conflitos de trabalho, e do sindicato único, de acordo com a profissão.

De modo que, o primeiro capítulo é teórico para compreender a ideia do solidarismo, do corporativismo, da igreja católica com suas encíclicas sociais e também da ideia que tinha do Brasil, de seu povo e classes políticas. 
ISSN 1981-3694

(DOI): $10.5902 / 1981369423065$

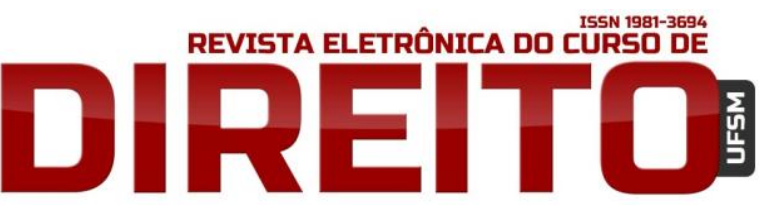

GRAND FINALE DA OBRA DE OLIVEIRA VIANNA EM NOSSA

CONSTITUIÇÃO?

MARCELO TOLOMEI TEIXEIRA DAURY CESAR FABRIZ

O segundo capítulo trata da criação da Justiça do Trabalho e das polêmicas sobre o poder normativo da mesma, capaz de solucionar com ponto final os conflitos trabalhistas, porém criticado tal solução como invasor da tripartição de poderes, ideia tão cara aos liberais da época.

No terceiro capítulo, aborda-se o sindicato, ligado ao Estado, em sua concepção corporativista e colaboracionista, afastado por completo da noção de luta de classe como o próprio Vianna definirá, e que é analisado ao longo do artigo.

\section{AS TEORIAS PRINCIPAIS}

Uma das características principais que Vianna enxerga no Brasil, é que o desenvolvimento do complexo rural transformou os latifúndios em pequenos universos econômicos, capazes de produzir quase tudo que precisavam e sem o menor estímulo, estável e previsível, à especialização e divisão do trabalho - daí a formação da "clã parental" -, sem comunicação entre si, sem interesses comuns, e sem ligação através do mercado"2.

Destarte, "isolacionismo" é uma palavra chave em Vianna e vai se contrapor a "solidarismo". A Constituição de 1891 simbolizava a realidade de um Brasil agrário, comandado por clãs, os "coronéis", incluindo o famoso "voto de cabresto", com um poder judiciário e aparelho policial corrompido pelos poderes locais. A referida Constituição, descentralizadora, adepta do federalismo só fazia ratificar tais princípios. 0 homem simples era isolado, estava na mão do proprietário rural, guiado pelos seus caprichos ou benevolência. No centro urbano, uma classe operária, era capacho de ideologias estranhas ao nosso povo - comunismo ou anarquismo. Vianna propunha um poder centralizador, um Estado forte, poder judiciário e polícia federalizada, uma política econômica ordenada. A democracia dita existente na atual Carta Política era uma fábula, importada dos americanos, ingleses ou franceses, de um povo cônscio de seus direitos e obrigações, que lutou para chegar a tal regime.

São muitas suas influências teóricas. Por exemplo, autores de linha corporativistas e pregadores do autoritarismo como Manoilesco, Perroux, Pirou, Panunzio, Lascki, no Brasil Alberto Torres (embora não fosse o mesmo um autor de ideias corporativas, mas de viés autoritário também) entre outros. Vamos, contudo, seguir Maria Stella Marins Bresciania e dar

\footnotetext{
${ }^{2}$ VIANNA, Oliveira. Instituições Políticas Brasileiras. 1. ed. Rio de Janeiro: EDUFF, 1987. p. 29.
} 
ISSN 1981-3694

(DOI): $10.5902 / 1981369423065$

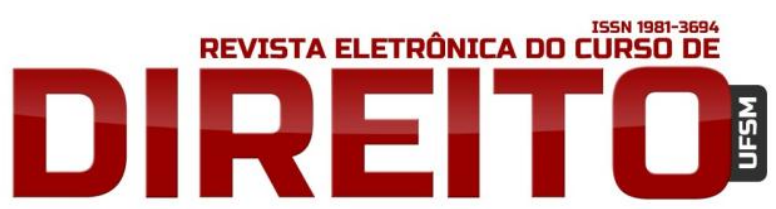

GRAND FINALE DA OBRA DE OLIVEIRA VIANNA EM NOSSA CONSTITUIÇÃO?

MARCELO TOLOMEI TeIXEIRA DAURY CESAR FABRIZ

ênfase nas ideias políticas do solidarismo francês como uma fonte privilegiada de Vianna até mesmo como forma de compreender melhor suas ideias sobre as relações trabalhistas.

Nesse passo, aponta-se em primeiro plano o autor francês Alfred Foillé como uma de suas principais afinidades teóricas. Tal movimento, surgido no início do século XX tem como perspectiva principal apresentar uma visão diferenciada do individualismo burguês e do exótico marxismo e seus derivados, uma autêntica terceira via, acreditando na cooperação e solidariedade, para proteger a dignidade humana. Converge também para tais ideias o jurista também francês Leon Duguit. Esse movimento surge na França por volta de 1900 e empolga Vianna. Era uma ideia apaziguadora, reformista. A crítica é no seguinte sentido: era uma solução em face da força que as lutas dos trabalhadores representavam - dentro de um viés marxista, por exemplo, é difícil não se inclinar para tal hipótese. Enfim, seus teóricos, não deixavam de enxergar a premente luta de classe caótica e acreditavam em um diálogo de integração via associações. Sendo que essa sociedade amistosa muito dependeria do Estado com forte presença na assistência social, educação e até no possível acesso à propriedade privada. Mais ainda: leis trabalhistas mínimas seriam regradas e seria o Estado julgador dos conflitos laborais. Educação seria fundamental para integrar os trabalhadores, promovida pelo Estado. Pode-se considerar que tal doutrina antecede a prática do Estado do Bem Estar social, tudo dirigido por um Estado científico, sabedor então da necessidade da integralização da classe trabalhadora. ${ }^{3}$

E nesse contexto, os solidaristas, já enxergavam a associação profissional como peça chave para a integração, ou seja, harmonizar patrões e empregados. No Brasil, para Vianna, era a possibilidade de esvaziar o egoísmo parental dos clãs, acreditando-se na "cooperação" dos homens, em seu gregarismo, por mais que isso fosse um processo lento e evidentemente, contando, com a batuta do Estado, que com dispositivos legais, estimularia a formação de Conselhos, em que a participação de produtores, trabalhadores e técnicos levariam nossa formação econômica e social para uma melhor sorte, daí a ideia do corporativismo.

Seu descrédito na classe política, nas velhas formas de debate parlamentares exclusivo fica evidente, o que vai, como já apontado, abrir uma crítica veemente dos liberais e dos marxistas quando discute-se o papel destinado à Justiça do Trabalho e dos sindicados. A rigor, ideia de corporativismo serviu a posições políticas diversas, exemplo típico foi o fascismo

${ }^{3}$ BRESCIANI, Maria Stela Martins. O charme da ciência e a sedução da objetividade. 1. ed. São Paulo: UNESP, 2005. p. 369-385. 
ISSN 1981-3694

(DOI): $10.5902 / 1981369423065$

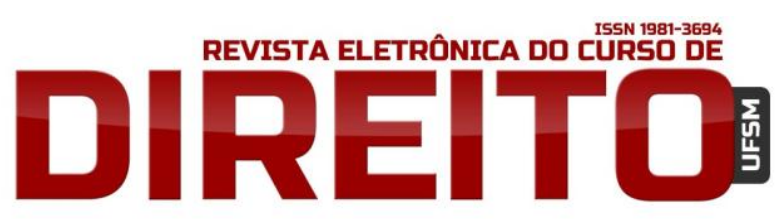

GRAND FINALE DA OBRA DE OLIVEIRA VIANNA EM NOSSA CONSTITUIÇÃO?

MARCELO TOLOMEI TEIXEIRA DAURY CESAR FABRIZ

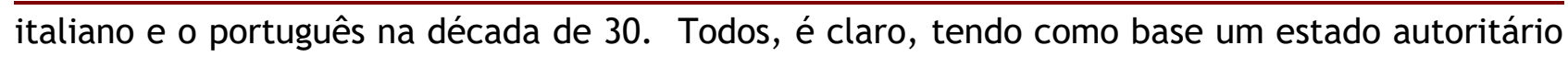
e centralizador.

Evaldo Amaro Vieira faz crítica interessante sobre o tema, baseado na ideia de incorporação da classe trabalhadora no estado capitalista, aliás capitalismo que Vianna em momento algum vem a criticar, já que seu projeto era de um reformismo, muitíssimo "bem comportado" já que acentuado nas paz social advinda do corporativismo:

Uma outra crítica ao Estado Corporativo está no ensaio de Vital Moreira. Sua interpretação parte do princípio de que o corporativismo de nossa época serve a determinada estrutura de poder econômico, social e político. Não se resume simplesmente a um ajuste de natureza institucional. 0 ideal corporativista moderno seria instrumento de supressão dos conflitos de classe através da repressão ou do controle das organizações profissionais. O Estado Corporativo consistiria num "certo tipo de Estado capitalista, de que faz parte necessariamente a integração das organizações operárias dentro do corpo estatal"4.

Pode-se também apontar como influência em Vianna a doutrina social da igreja católica, consolidadas nas encíclicas Rerum Novarum de Leão XIII e Quadragésimo Ano de Pio XII, que pregavam a humanização nas relações de trabalho, e que continham críticas ferrenhas aos movimentos comunistas e seus correlatos como também ao liberalismo indiferente que era a questão social de um proletariado que vivia em precárias condições de sobrevivência. 0 que, com certeza, deu ainda mais fôlego para a chamada terceira via da era Vargas, Vianna era católico, mas na sua situação de homem de ciência, não apelou para tais doutrinas no embate em que travou defendendo suas ideias.

Por seu turno, a chamada Escola Sociológica do Direito Norte-Americano ou Realismo Jurídico foi arma vital para seus embates, como nas análises abaixo sobre a Justiça do Trabalho e os sindicatos. Por ora, contudo, a síntese perfeita é realizada por Evaldo Amaro Vieira, que situa os principais autores americanos utilizados por Vianna:

Harmoniza-se com as preocupações de Cardozo, quanto à necessidade de o julgador atentar à realidade social, abandonando, se necessário a precedência da lei para valorizar o sentimento de justiça ou o bem-estar social. Holmes trilha iguais pontos de vista, com poucas alterações. A Escola Sociológica do Direito expressa-se radicalmente através do Realismo Jurídico Norte-Americano, cuja tendência central se caracteriza pelo menosprezo da norma, reduzindo o Direito a um conjunto de fatos. Os fatos pesam e determinam as decisões. 0 direito surge do fato e não da norma: aqui se localiza Bradeis. Privilegia especialmente os conhecimentos sociológicos e econômicos na formação do jurista, atuando

\footnotetext{
${ }^{4}$ VIEIRA, Evaldo Amaro. Oliveira Vianna e o Estado Corporativo. 1. ed. São Paulo: Grijalbo, 1976. p. 19.
} 
ISSN 1981-3694

(DOI): $10.5902 / 1981369423065$

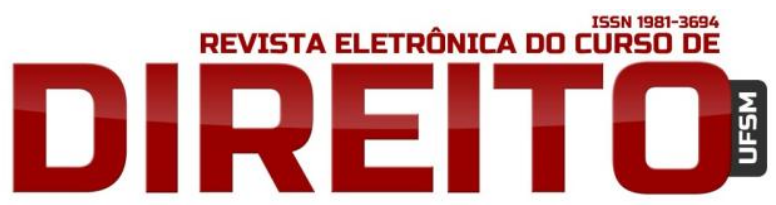

GRAND FINALE DA OBRA DE OLIVEIRA VIANNA EM NOSSA CONSTITUIÇÃO?

MARCELO TOLOMEI TEIXEIRA DAURY CESAR FABRIZ

sempre com o fim de separar interpretação de aplicação da lei. Haja vista o destaque atribuído a esta última por Brandeis, porque "na maioria das questões estabelecer a regra aplicável é mais importante do que estabelecê-la acertadamente"' como diz no debate do caso Burnet v, Coronado Oil and Gas $\mathrm{Co}^{5}$.

Todos os juristas citados abandonam o método exegético ou gramatical, admitindo que a lei pode ser redefinida pelos fatores sociológicos e econômicos, de fato é uma modernidade para época, em especial para nossa cultura jurídica, engessada pela busca do sentido unívoco da lei. Trata-se, então, da noção, como muitos gostam de conduzir, que o direito é vivo, sendo irresistível não cuidar de sua atualização. 0 professor Luis Alberto Warat afirmava que o método sociológico, viés principal desses autores citados, "substitui o culto à lei pelo culto aos dados"6. Cabe o questionamento, portanto, se a interpretação dos dados é de fato neutra, inclusive, à escolha dos dados que o jurista pretende trabalhar, o que pode levar sempre para uma escolha ideológica do intérprete, sem qualquer neutralidade, escondendo, a rigor, as opções de valores do jurista. Enfim, volta-se a tal discussão, pois se passa a falar sobre a criação, papel e polêmicas sobre a Justiça do Trabalho.

Emblemático que, ao criticar a figura de Rui Barbosa em uma de suas obras, Vianna o faça de forma parcimoniosa, reconhecendo o valor do artífice da Constituição de 1891 e atribuindo que suas acepções erradas da realidade social, política e jurídica, decorreram da impossibilidade do jurista baiano, não ter tido a oportunidade de conhecer um estado da arte que Vianna conhecia então. Vai então traçar um verdadeiro roteiro de sua acepção sobre o que considera essencial em termos de teoria. Enumera em primeiro plano o advento das Ciências Sociais: dentro das regras de uma metodologia rigorosamente objetiva, com os recursos da análise matemática e das pesquisas e investigações de campo (Weber, Ehrilich, Durkheim, etc) ${ }^{7}$.

Continua, aduzindo que faltou a Rui o conhecimento do estudo do Direito Público, do Direito Constitucional e do Direito Administrativo, calcado agora na investigação concreta e realística, ou seja, na escola sociológica americana a new jurisprudence school calcado em Holmes, Pound, Cardozo, etc. Usa o termo pragmatismo como "interpretar não mais para uma sociedade ideal; mas, sim objetivamente - dentro das condições atuais da vida americana, tais como essas condições aparecem nos labores e pesquisas dos economistas e demais sabedores das ciências sociais"8.

\footnotetext{
${ }^{5}$ VIEIRA, Evaldo Amaro. Oliveira Vianna e o Estado Corporativo. 1. ed. São Paulo: Grijalbo, 1976. p. 63.

${ }^{6}$ WARAT, Luiz Alberto. Introdução Geral ao Direito. 1. ed. Porto Alegre: Sergio Fabris, 1994. p. 84.

${ }^{7}$ VIANNA, Oliveira. Instituições Políticas Brasileiras. 1a ed. Rio de Janeiro: EDUFF, 1987. p. 51.

${ }^{8}$ Ibidem. p. 54.
} 
ISSN 1981-3694

(DOI): $10.5902 / 1981369423065$

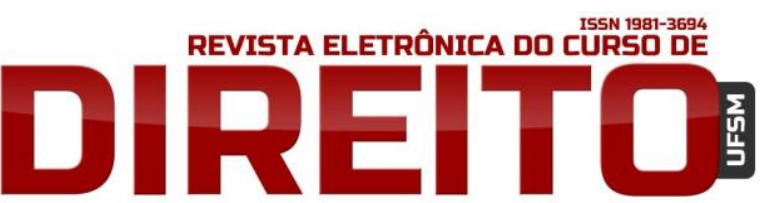

GRAND FINALE DA OBRA DE OLIVEIRA VIANNA EM NOSSA

CONSTITUIÇÃO?

MARCELO TOLOMEI TEIXEIRA DAURY CESAR FABRIZ

E, por fim, faltou a Rui conhecer as enormes e complexas transformações advindas com a primeira conflagração mundial (1914-1918), a consolidação do Direito do Trabalho e do Direito Corporativo, a substituição do primado do Poder Legislativo, a possibilidade da substituição do sufrágio universal pelo sufrágio corporativo ou os partidos políticos pelos grupos profissionais. Destarte, compreendendo melhor as ideias de Vianna, parte-se agora9 para a análise da formação da Justiça do Trabalho que será, como se vê a seguir, calcada em suas ideias políticas e jurídicas.

\section{PROJETO DE JUSTIÇA DO TRABALHO E SUA TRADIÇÃO EM NOSSAS CONSTITUIÇÕES}

Vigorava a Constituição de 1934, liberal demais para a geração varguista com notória vontade de centralização de poder e autoritarismo. Vianna apresenta seu projeto de Justiça do Trabalho. Nesse contexto, Vianna trava seu grande primeiro debate público, tendo como algoz o jurista paulista e representante da FIESP Waldemar Ferreira, relator do projeto na Câmara dos Deputados. Os argumentos de defesa apresentado por Vianna se encontram em sua obra "Problemas de Direito Corporativo", que, aliás, trata-se de cópia dos diversos artigos publicados na imprensa através dos quais Vianna responde as críticas de Ferreira que dizia que o projeto era inconstitucional em muitos pontos, criticando ainda o caráter fascista de seus dispositivos. E a polêmica essencial gira em torno do poder normativo atribuído a Justiça do Trabalho, ou seja, sua competência para leis, com seu natural caráter abstrato de envolver todos os membros das categorias profissionais envolvidas em conflitos coletivos.

0 arsenal jurídico utilizado por Vianna é "pesado", no sentido de sua atualização com as ideias da modernidade jurídica e sociológica, transpassa ainda uma necessidade assaz em demonstrar que seu projeto não é criado dentro dos quadrantes fascista. A ideia central de Ferreira era de que não caberia aos juízes do trabalho instituírem tais leis para as categorias em conflito, pois que tal feria de morte a tradicional tripartição de poderes do regime democrático.

Destarte, Vianna trata de apontar que novos métodos de exegese constitucional, estão sendo utilizados na atualidade. Que o essencial é procurar nas realidades sociais e nos imperativos do interesse público os elementos de inspiração para a exegese constitucional, daí cita Holmes, Brandeis, Stone, Cardozo como autores de espírito pragmatistas, que vislumbram

\footnotetext{
${ }^{9}$ VIANNA, Oliveira. Instituições Políticas Brasileiras. 1a ed. Rio de Janeiro: EDUFF, 1987. p. 56.
} 
ISSN 1981-3694

(DOI): $10.5902 / 1981369423065$

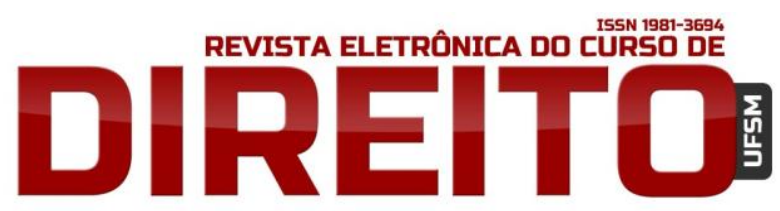

GRAND FINALE DA OBRA DE OLIVEIRA VIANNA EM NOSSA

CONSTITUIÇÃO?

MARCELO TOLOMEI TEIXEIRA DAURY CESAR FABRIZ

que a lógica da sociedade deve prevalecer sobre a lógica das palavras. Além disso, relembra autores, que apontam que o Estado deixou de ser a única fonte jurídica (Geny e Eherlich). E ironiza o ambiente de nossa inteligência jurídica no sentido de que nossos juristas são civilistas, comercialistas, processualistas notáveis, ou grandes advogados, ou seja, possuem dificuldades para compreenderem o papel do Direito Público no mundo moderno. ${ }^{10}$

A delegação de poderes passa a ser seu foco, óbvio por conta dos poderes que pretende atribuir para Justiça do Trabalho como árbitra dos conflitos trabalhistas, daí afirmar que o poder normativo não contraria os princípios da Constituição Federal em voga, apontando ser enfoque da modernidade a delegação dos mesmos quando se trata de matéria de ordem pública, higiene pública e interesses econômicos e sociais, descentralização funcional ou institucional, em prol da eficiência dos serviços. Fala em plasticidade e adaptabilidade necessária e cita o exemplo de descentralização dos norte-americanos com suas agências regulamentadoras. Aponta ainda que, no Brasil, tal descentralização já era conhecida com o Departamento Nacional do Café e Instituto do Álcool ${ }^{11}$.

Aduz que a modernidade processual também garante a correta acepção do poder normativo vide a possibilidade dos tribunais julgarem com caráter dispositivo e, portanto, normativo. Sendo que no campo trabalhista os conflitos coletivos pedem naturalmente regulamentação coletiva, já no campo dos conflitos individuais trabalhistas os tribunais aplicam as leis para os litigantes in specie, devendo, contudo, ser de forma rápida, simplista, alargando a benevolência e equidade - mas não deixa de ser uma sentença típica. Chega a citar a distante Nova Zelândia, que dispõe de seu poder normativo nos seus tribunais, como forma demonstrar que a instituição nada tem haver com o fascínio italiano ${ }^{12}$. Vale registrar que toda a lógica da Carla del Lavoro e da própria lei de sindicalização italiana (art.16 da Lei 563/16) tem como perspectiva teleológica equilibrar os interesses dos empregadores, com o dos trabalhadores e proteger, em qualquer caso, os interesses da produção, o que certamente levava seus críticos a fazerem analogias como os propósitos do projeto de Vianna.

Vianna explica, então, a base de um julgamento de uma sentença coletiva, ou seja, como criar uma norma reguladora? Fala, então, em senso de realidade prática: equidade

\footnotetext{
${ }^{10}$ VIANNA, Oliveira. Problemas de Direito Corporativo. 1a ed. Rio de Janeiro: José Olympio, 1938. p. 1324.

${ }^{11}$ Ibidem. p. 28-32.

12 Ibidem. p. 46-49.
} 
ISSN 1981-3694

(DOI): $10.5902 / 1981369423065$

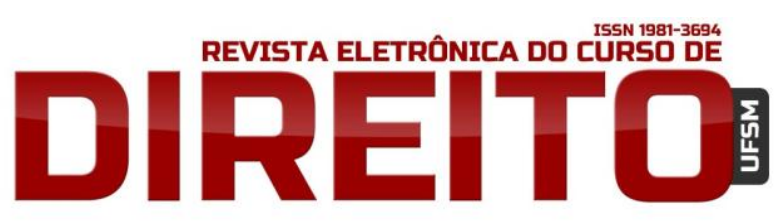

GRAND FINALE DA OBRA DE OLIVEIRA VIANNA EM NOSSA CONSTITUIÇÃO?

MARCELO TOLOMEI TEIXEIRA DAURY CESAR FABRIZ

significa ponderar preços, custos e métodos de produção e interesses da nação, significa, então, balanceamento. Cita-se diretamente sua acepção:

Esta sentença é uma composição de interesses econômicos entre as duas categorias em conflito, de caráter forçosamente temporário, porque sempre formulada por um prazo determinado, não longo; composição fundada em cálculos de custos de produção e de rentabilidade da empresa, de condições de vida (standart of living) e condições de mercado, dados estes que sofrem variações frequentes, com reflexo necessário sobre o nível dos salários" ${ }^{13}$.

Sua crença no poder normativo proposto é gritante, acreditando em sua capacidade real para resolver os conflitos coletivos trabalhistas, evitando assim, o conflito, a necessidade da força policial que entende ter sido utilizada de forma recorrente, chegando às vias de citar a famosa frase do presidente Washington Luis de que, no Brasil, a "questão social" era uma questão de polícia, cita-se diretamente sua profecia:

[...] tais conflitos que são socialmente os mais importantes pelas suas repercussões sobre a ordem pública e social, voltarão a ser novamente o que haviam deixado de ser, isto é "questão de polícia", decididos a golpes de chanfralho e a pata de cavalo nas correrias da praça pública - hipótese em inteira contradição com o próprio ato do legislador constituinte, instituindo a Justiça do Trabalho"14.

Sua proposta foi recusada, prevalecendo o voto contrário de Waldemar Ferreira. Contudo, após a Constituição de 1937, o projeto de Vianna se consolida mediante o Decreto-lei n. 1237/39, que aprovou a Justiça do Trabalho, com a originalidade da representação classista e do poder normativo. Sendo que a Constituição de 1946 admitiu limitado seu exercício pela lei ordinária, mesma orientação da Lei Suprema de 1967 e a Emenda de 1969. A Constituição de 1988 manteve a tradição determinando em seu art.144 que "frustrada a negociação coletiva, as partes poderão eleger árbitros", contudo, seu parágrafo segundo aponta que "Recusando-se qualquer das partes à negociação ou arbitragem, é facultado aos respectivos sindicatos, ajuizar dissídio coletivo, podendo a Justiça do Trabalho, estabelecer normas e condições, respeitadas as condições convencionais e legais mínimas de proteção ao trabalho".

Verdade que a Emenda Constitucional n. 45 trouxe mudanças na atual Constituição de 1988: já que o comum acordo das partes passou a ser pressuposto para impetração do dissídio coletivo, sendo que nas chamadas atividades preponderantes o Ministério Público do Trabalho

\footnotetext{
${ }^{13}$ VIANNA, Oliveira. Problemas de Direito Corporativo. 1a ed. Rio de Janeiro: José Olympio, 1938. p. 58. ${ }^{14}$ Ibidem. p. 54.
} 
ISSN 1981-3694

(DOI): $10.5902 / 1981369423065$

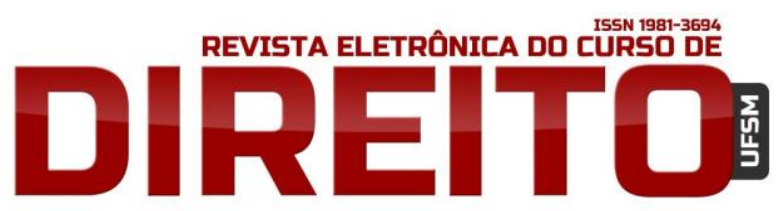

GRAND FINALE DA OBRA DE OLIVEIRA VIANNA EM NOSSA

CONSTITUIÇÃO?

MARCELO TOLOMEI TEIXEIRA DAURY CESAR FABRIZ

também tem legitimidade. Porém, para declaração de abusividade de greve, o sindicato patronal ou empresa afetada possui legitimidade para interpor a ação de dissídio coletivo, o que faz com que, na prática, a Justiça do Trabalho acabe a intervindo na luta de classes.

Certo ou errado, a arquitetura de Vianna continua de pé. Passou pelos mais variados regimes políticos. Sofreu e sofre inúmeras críticas: a começar pela liberal, que não admite o Judiciário constituindo leis para as partes envolvidas; pela própria recomendação da Organização Internacional do Trabalho (n.92/51) que prefere a arbitragem facultativa para solução dos conflitos trabalhistas; pela timidez do Judiciário em impor cláusulas novas; pelo apressamento nos julgamentos - via de regra - para por fim a movimentos grevistas; pelas limitações que o Executivo impunha com sua política salarial engessada (na época da ditadura de 64 foi fato); por tornar a classe trabalhadora preguiçosa por preferir, muitas vezes, esperar pelo julgamento do dissídio do que se mobilizar e negociar com o patronato; e, por outro lado, inibir o movimento de liberdade grevista.

Por seu turno, recebe elogios, já que não impede a solução dos conflitos pela via de negociação, ou seja, através dos acordos e convenções coletivas; por possibilitar sindicatos de poder de mobilização limitado de obter talvez ganhos pela decisão do dissídio; e, principalmente, por solucionar conflitos que poderiam se arrastar prejudicando a produção e dependendo do caso a própria população. Enfim, o importante é frisar, que tal modelo, obra de Oliveira Vianna, adentrou de fato em nossas tradições constitucionais.

Por fim, mas sem maiores detalhamentos ante o espaço do artigo, que o modelo de Justiça do Trabalho composta por juízes técnicos e leigos (classistas) chegou a perpassar por diversas constituições, até mesmo a de 1988, sendo extinta com o advento da Emenda Constitucional n.24, de 09.12.1999, que extinguiu a representação classista, ouvindo os apelos dos advogados e juízes togados, ante a apontada inoperância e custos de tais juízes. Contudo, a Justiça do Trabalho, antes da aludida Emenda, era composta pelas chamadas Juntas de Conciliação e Julgamento na primeira instância, os Tribunais Regionais de Trabalho na segunda e até o Tribunal Superior do Trabalho na terceira e todas compostas por representantes dos empregados e empregadores. Nas Juntas, que depois passou a ser denominadas Varas, a presidência era de um juiz de carreira, nas demais instâncias tinham assento, de forma proporcional, também tais representantes, ou seja, uma arquitetura típica do corporativismo de Vianna. 


\section{O PROJETO DE SINDICATO E SUA TRADIÇÃO EM NOSSAS CONSTITUIÇÕES}

0 que se espera de um sindicato? Naturalmente que lute pelos interesses de sua categoria, sendo certo que para um marxista ou anarquista, escolado da ideia da tomada do estado burguês, pelo menos na época de Vianna, também seria oportunidade de um salto na consciência da classe trabalhadora para tal necessidade histórica. Vianna também tem essa ideia de "paideia" dos sindicatos, só que evidentemente, a consciência é no sentido de colaboração com o Estado da hora, ou seja, o Estado Novo e seus ideais corporativistas, era uma saída para o isolacionismo de nossa gente.

Destarte, ao atacar o sufrágio universal, aponta que só agora - com a organização sindical das classes - é que as nossas populações (e só urbanas) estão começando a praticar uma autêntica democracia direta - que é o sindicato de classe. E diz que só concederia o direito de sufrágio ao cidadão sindicalizado, ao homem do povo que fosse molécula de qualquer associação extrapessoal, citando até as associações de escoteiros (sic) com tal perspectiva ${ }^{15}$.

Em sua obra "Problemas de Direito Sindical", narra sua "odisséia" para aprovação de suas ideias, de um sindicato "neutro", único e colaborador do Estado. Não é plausível considerar que tal quadro tornaria o eleitor capaz e livre, ainda mais quando tal consciência seria tutelada pelo Estado, pela figura do "pelego", presidentes de sindicatos burocráticos, sem vínculo real com os interesses da categoria, interessados sim nas benesses do imposto sindical e acomodado com as decisões da Justiça do Trabalho nos dissídios coletivos.

Enfim, para ótica de Vianna, a luta de classe terminou, o corporativismo amarra os interesses de patrões e empregados que passam a dirigir também o Estado, Evaldo Amaro Vieira, faz observação escorreita sobre o tema merecendo citação direta:

Pondo de lado as observações de Oliveira Vianna referentes ao Estado Novo, é importante considerar o que ele vê de revolucionário no corporativismo. A organização corporativa transforma a mentalidade operária, desintegrando-lhe o 'espírito antipatronal' e o 'sentimento de inferioridade', porque 'coloca no mesmo pé de igualdade, o patrão e o empregado'. O igualitarismo corporativista é uma solução extremamente louvada por Oliveira Vianna: no passado, diz-nos, o operário jamais passou em vir a figurar nas camadas dirigentes, ao passo que agora, 'sem deixar de ser um operário', coloca-se no mesmo nível das classes

\footnotetext{
${ }^{15}$ VIANNA, Oliveira. Instituições Políticas Brasileiras. 1a ed. Rio de Janeiro: EDUFF, 1987. p. 123.
} 
ISSN 1981-3694

(DOI): $10.5902 / 1981369423065$

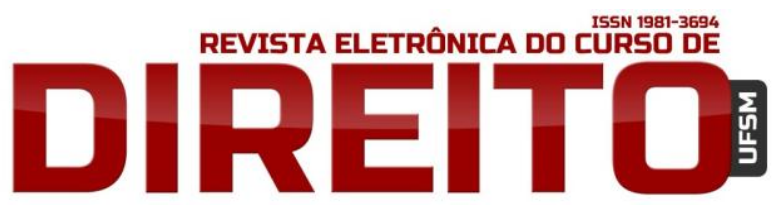

GRAND FINALE DA OBRA DE OLIVEIRA VIANNA EM NOSSA CONSTITUIÇÃO?

MARCELO TOLOMEI TeIXEIRA DAURY CESAR FABRIZ

superiores. Tal é o 'milagre desses novos tempos, dos sistemas paritários, dos regimes corporativos, que aboliram as distâncias sociais ${ }^{16}$.

Destarte, seguindo as linhas de sua obra "Problemas de Direito Sindical", Vianna decreta que o sindicalismo, oriundo do Estado Novo, está liberto da preocupação da luta de classes ${ }^{17}$, daí acreditar no seu papel grandioso de seu solidarismo. Ora, entra aqui, o chamado mito da outorga, ou seja, de "começar tudo do zero". Evaristo de Moraes Filho vai chamar de esquecimento ${ }^{18}$, que a geração de Vargas faz, omitindo da luta de classe da era da República Velha, que deflagrou inúmeras greves, que obteve inúmeras leis trabalhistas, que consolidou sim uma consciência de classe e que quando não esquecida e apresentada como fase negativa de nosso sindicalismo como indubitavelmente faz Vianna. O mito conta uma realidade: a chegada de Vargas ao poder, o "pai dos pobres", que dá ao trabalhador uma dignidade que tem que ser reconhecida pelas elites. A rigor, é a terceira via que se apresenta, vinda do solidarismo, acima tratado, fugindo do liberalismo e do comunismo exótico e que se torna realidade entre nós através de um Estado centralizador e autoritário.

A exacerbação mencionada é assim exposta por Evaristo de Moraes Filho: "depois de 1930 no Brasil, houve um excesso da valorização e de elogios à obra do novo governo, com a correspondente subestimação dos movimentos operários e das ideias dos doutrinadores trabalhistas do período anterior. Diziam os adeptos do Ditador da hora que nada havia sido feito, que a legislação foi outorgada às massas, surpresas e agradecidas"19. A matéria é rica com vários dados históricos, inclusive de citações dos movimentos grevistas que existiram, dos diplomas legais surgidos antes de trinta, com várias negociações coletivas existentes e os discursos da geração pós-trinta com as exacerbações sugeridas por Evaristo de Moraes Filho.

Contudo, um ponto positivo de Vianna, ele também criticava as elites econômicas. Em uma passagem de "Problemas de Direito Sindical", aduz diálogo com um empresário após palestra que proferiu, quando afirmou que as empresas seriam governadas por corporações (empregados empresários - e Estado), e ouve do mesmo de que "agora seriam escravizados". Daí conclui que os capitães de indústrias, eram despreparados para a realização do Estado Moderno ${ }^{20}$.

\footnotetext{
${ }^{16}$ VIEIRA, Evaldo Amaro. Oliveira Vianna e o Estado Corporativo. 1. ed. São Paulo: Grijalbo, 1976. p. 67.

${ }^{17}$ VIANNA, Oliveira. Problemas de Direito Sindical. 1. ed. Rio de Janeiro: Max Limonad, 1943. p. 12.

${ }^{18}$ MORAES FILHO, Evaristo. O Problema do Sindicato Único no Brasil. 2. ed. São Paulo: Alfa-Omega, 1952. p. 193-199.

19 Ibidem. p. 181.

${ }^{20}$ VIANNA, Oliveira. Problemas de Direito Sindical. 1. ed. Rio de Janeiro: Max Limonad, 1943. p. 53.
} 
ISSN 1981-3694

(DOI): $10.5902 / 1981369423065$

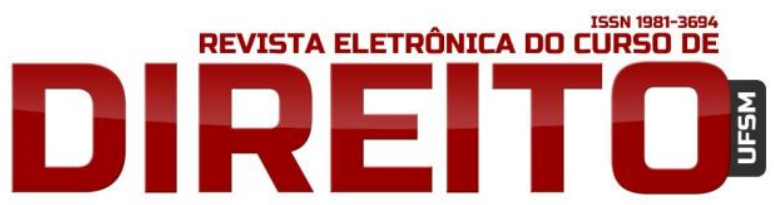

GRAND FINALE DA OBRA DE OLIVEIRA VIANNA EM NOSSA CONSTITUIÇÃO?

MARCELO TOLOMEI TeIXEIRA DAURY CESAR FABRIZ

Voltando para seu projeto específico da lei sindical, como pilar está sua defesa intransigente do sindicato único. E, para tal, aduz que o sindicato único foi consagrado pela exegese da nova Constituição de 1937. É que uma corrente de liberais e católicos defendia a pluralidade com respaldo na mesma, o que - segundo Vianna - seria equivocado. Isso porque, seus adversários argumentavam o pluralismo sindical por conta do art. 138 da referida Carta Política, que aduzia que a "associação profissional ou sindical é livre". Vianna vai então argumentar que tal seria impossível já que por conta da mesma Constituição o sindicato representa toda a categoria e não apenas seus associados - art. 137, alínea "a" da Constituição Federal de $1937^{21}$. E que, portanto, seria impraticável uma pluralidade sindical. Tal exegese foi amplamente vencedora, seja pela realidade da lei ordinária (CLT), seja pelo controle que o Ministério do Trabalho e a Justiça do Trabalho fizeram sobre o tema. Destarte, a liberdade tratada seria apenas a liberdade individual de associar-se onde e quando entender.

Os sindicatos, dentro do projeto vitorioso de Vianna, são entidades públicas, colaboradoras do Estado, não são associações privadas justamente pela perspectiva de apresentarem via convenção coletiva um regulamento para toda a profissão, pode-se ainda pensar, matéria que é tratado adiante, de ser recolhedora do imposto sindical. Enfim, para sua lógica: "dentro de um regime de sindicatos múltiplos para cada categoria e organizados autonomicamente, isto é, libertos do controle do Estado, não seria possível a este, evidentemente às atividades econômica da Nação uma determinada orientação ou realizar determinada política econômica nacional"22. E segundo sua prática, quando da vigência do pluralismo sindical (a Constituição Federal de 1934 de fato assim previa) houve um fator de lutas, de anarquias e de enfraquecimentos. Toda essa visão denota bem todo o dirigismo estatal que pretende para as entidades sindicais - órgãos constitutivos de governos e limitados à defesa dos interesses profissionais, afastando sindicatos de combate ou confessionais (ligados a um credo religioso).

Defende ainda tal opção como não fascista. Diz para tal, que a par do espírito da época, não optou em seu projeto na nomeação pela autoridade administrativa dos presidentes das associações sindicais e que em suas palavras: "o Fascismo havia transformado o sindicato em órgão de partido e instrumento dele, dando-lhe uma coloração estritamente partidária"23. Contudo, não negava a vigilância e possível intervenção do Estado na vida sindical, o que

\footnotetext{
${ }^{21}$ VIANNA, Oliveira. Problemas de Direito Sindical. 1. ed. Rio de Janeiro: Max Limonad, 1943. p. 43-52.

22 Ibidem. p. 56.

${ }^{23}$ Ibidem.
} 
ISSN 1981-3694

(DOI): $10.5902 / 1981369423065$

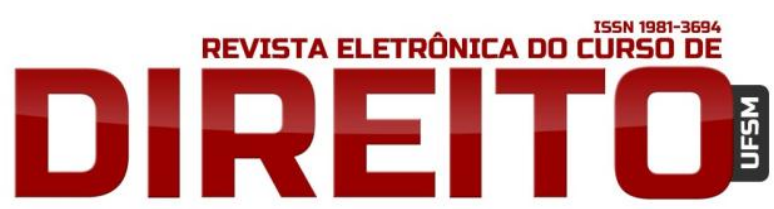

GRAND FINALE DA OBRA DE OLIVEIRA VIANNA EM NOSSA CONSTITUIÇÃO?

MARCELO TOLOMEI TeIXEIRA DAURY CESAR FABRIZ

demonstra a vocação de autoritarismo preconizado por Vianna, já que o Estado poderia intervir no controle de aprovação das diretorias eleitas; no controle de destituições das diretorias infratoras das leis sindicais e das finalidades associativas; poderia intervir no caso de irregularidades e conflitos internos, atos ilegais, entre outros. Enfim, o culto ao Estado, leia-se aos poderes quase que absolutos do Ministério do Trabalho sobre a vida dos sindicatos e que, na verdade, eram insuportavelmente castradores para uma ideia mínima de liberdade sindical.

Detestando sempre a cópia de institutos que nada teriam com nossa formação Vianna afiançava que a nova Lei Orgânica Profissional tinha as peculiaridades de nossa cultura e estrutura econômica. E que a nova legislação sindical não tinha similar no mundo todo, que estava dentro de um quadrante de uma democracia autoritária e não totalitária e isso se refletia o Quadro das Atividades e Profissões que produziu²4. Quadro esse que era verdadeiramente uma "camisa de força", cabendo ao Ministério do Trabalho definir a possibilidade ou não de um sindicato ser criado.

Evaristo de Moraes Filho, que também defende o modelo de sindicato único, revolta-se, quanto ao clima da época, ou seja, de autoritarismo do Ministério do Trabalho, pois que os sindicatos nascem, vivem e morrem pela vontade do referido Ministério, valendo a pena também citação direta de seu quase grito de revolta.

Lembra-se aqui aquela frase do próprio Oliveira Vianna, citada páginas atrás - o sindicato único não se nega; conquista-se. De fato. Dentro do mesmo sindicato unitário pode chegar aos cargos diretivos justamente a corrente de oposição aos poderes constituídos, contrária a essa tão proclamada tutela. Isso ocorreu recentemente entre nós nos sindicatos dos bancários e dos securitários desta Capital. E qual foi a única saída do Ministério? Decretar a intervenção com fundamento no art. 529. Logo, o mal não está na forma do sindicato único, e sim na falta de autonomia sindical, que é outra história bem diversa ${ }^{25}$.

Outro jurista, Arnaldo Sussekind, lembra que a unicidade sindical foi adotada de forma obrigatória na União Soviética e defendida pelos franceses solidaristas como Maxime Leroy ${ }^{26}$. Enfim fascista ou não, foi o modelo que predominou e que ganhou carreira em nossas constituições.

\footnotetext{
${ }^{24}$ VIANNA, Oliveira. Problemas de Direito Sindical. 1. ed. Rio de Janeiro: Max Limonad, 1943. p. 53.

${ }^{25}$ MORAES FILHO, Evaristo. O Problema do Sindicato Único no Brasil. 2. ed. São Paulo: Alfa-Omega, 1952. p. 100.

${ }^{26}$ SUSSEKIND, Arnaldo. Curso de Direito do Trabalho. 1. ed. Rio de Janeiro: Renovar, 2002. p. 70.
} 
ISSN 1981-3694

(DOI): $10.5902 / 1981369423065$

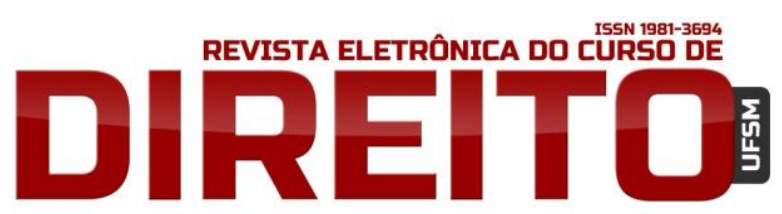

GRAND FINALE DA OBRA DE OLIVEIRA VIANNA EM NOSSA

CONSTITUIÇÃO?

MARCELO TOLOMEI TEIXEIRA DAURY CESAR FABRIZ

É claro que a redemocratização do país, via Constituição de 1988, trouxe a liberdade sindical no campo político, sua autonomia de gestão e o sindicato passou a ser pessoa jurídica privada. Como indica Delgado, os traços mais marcantes do autoritarismo foram afastados, mas não outros. De modo que, intacto ficou a unicidade sindical compulsória por categoria e as contribuições obrigatórias em favor das associações que formam o sistema confederativo de representação sindical - vide o artigo $8^{\circ}$, incisos II e IV de nossa atual Constituição Federal. E tudo isso ao arrepio da Convenção 87 da Organização Internacional do Trabalho, que o Brasil não ratificou que prega a pluralidade sindical ${ }^{27}$.

A questão da uniciadade ou pluracidade sindical deveria caber para as próprias organizações sindicais resolverem como bem define Delgado: "o sistema da liberdade sindical, seja com pluralismo, seja com unicidade prática de sindicatos, prepondera na maioria dos países ocidentais desenvolvidos (França, Inglaterra, Alemanha, EUA, etc.). Nos países em que há unidade prática de sindicatos (caso da Alemanha), ela resulta da experiência histórica do sindicalismo e não da determinação legal"28.

Lembramos que atualmente cabe para Justiça do Trabalho definir a possibilidade ou não de um sindicato vir a ser criado ou desmembrado, e curiosamente é matéria deveras complexa já que não temos a rigor um norte na Lei a não ser a exigência constitucional. Surgem embates sobre a legalidade de sindicatos que são criados e questionados por outra entidade sindical que entende que sua base está sendo invadida, mas não cabe aqui esmiuçar essa tormentosa questão.

Por seu turno, o imposto sindical, hoje denominado contribuição sindical, é receita taxa uma única vez em favor do sistema sindical, nos meses e valores montantes determinados pela CLT, mas que foi garantido também pelo art. $8^{\circ}$, inciso IV da Constituição Federal. 0 que poderia se justificar pelo caráter público do sindicado de outrora, mas não mais agora com a privatização dos sindicatos. Ademais, sempre foi uma forma de garantir nos sindicatos dirigentes "pelegos", que não se esforçavam em reconhecimento real de sua categoria, capaz de sustentar o sindicato, já que isso era garantido por tal verba.

Enfim, a par de todas as críticas feitas ao engenho de Vianna, a verdade é que assim como seu modelo de poder normativo permaneceu, seu modelo de sindicalismo, tirando os excessos de autoritarismos também. Poderia ser diferente? Talvez, muitos apontam que seu modelo inibiu o fortalecimento dos sindicatos e um direito do trabalho calcado muito mais na

\footnotetext{
${ }^{27}$ DELGADO, Mauricio Godinho. Curso de Direito do Trabalho. 9. ed. São Paulo: LTR, 2012. p. 211.

${ }^{28}$ Ibidem. p. 213.
} 
ISSN 1981-3694

(DOI): $10.5902 / 1981369423065$

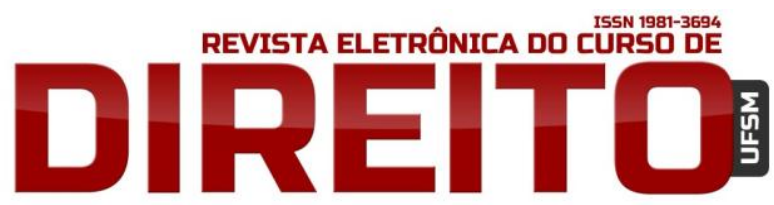

GRAND FINALE DA OBRA DE OLIVEIRA VIANNA EM NOSSA

CONSTITUIÇÃO?

MARCELO TOLOMEI TEIXEIRA DAURY CESAR FABRIZ

negociação coletiva. Mas é difícil prever o andamento da história, um modelo, por exemplo, que se baseasse no negociado, sem uma legislação social constitucionalizada e meticulosa, talvez estivesse mais sujeita aos ventos liberalizantes da atualidade, que diminuem a cada dia, ou tentam, os direitos sociais vigentes. A história tem suas ironias e quiçá faça repensar os críticos mais veementes de Vianna, desde é claro sejam os mesmos comprometidos com a função social do Direito do Trabalho.

\section{CONCLUSÃO}

Oliveira Vianna pensou o Brasil de forma densa e original. Mais do que pensar, acreditou num modelo de estado corporativo, viveu intensamente a política da era Vargas e vários de seus projetos no campo trabalhista foram implantados e refletem ainda hoje em nossa Constituição Federal, notadamente seus ideais do poder normativo da Justiça do Trabalho e de sindicato único.

Ao pensar o Brasil, criticou no campo político e jurídico, as ideias importadas do liberalismo, como cópia de modelos de povos europeus e norte-americanos, que lutaram por conquista de liberdade política e direitos civis. Nesse quadrante, a Constituição de 1891, era uma farsa com nossa gente pobre, pois veio a privilegiar o federalismo e uma representação política que só fortaleceu os clãs locais com seus privilégios, negando na prática os direitos civis de nossa gente.

Seu descrédito na política tradicional era, portanto, total. Começar um novo país era dar credibilidade a um estado autoritário, capaz de tirar o povo brasileiro de seu isolacionismo, romper as barreiras de uma elite que só pensava em si e apostar que tudo poderia se modificado com a implantação desse estado corporativista. A intervenção do Estado, longe das concepções liberais, que procurava justamente proteger o cidadão de suas garras, seria a salvação do povo contra as criticadas oligarquias.

Portanto, o Estado Corporativo era uma possibilidade para afirmação do centralismo, da autoridade, da comunhão das classes, do nacionalismo e da fé cristã. No campo trabalhista, o solidarismo francês, incorpora os trabalhadores, nesse estilo de Estado, representando uma terceira via, que contrasta com o liberalismo e as ideias socialistas, comunistas e anarquistas. 0 sistema é capitalista, mas viabiliza os direitos trabalhistas com um Estado interventor no conflito de classes e garantidor de direitos materiais da classe operária. As corporações permitem o 
ISSN 1981-3694

(DOI): $10.5902 / 1981369423065$

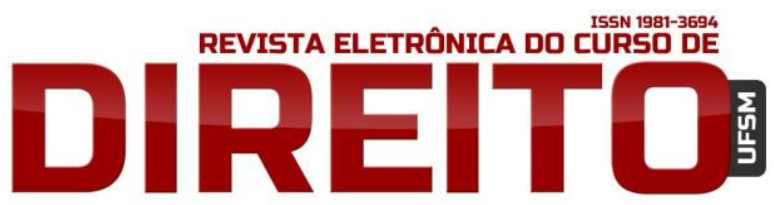

GRAND FINALE DA OBRA DE OLIVEIRA VIANNA EM NOSSA CONSTITUIÇÃO?

MARCELO TOLOMEI TEIXEIRA DAURY CESAR FABRIZ

entendimento de classe - a paz social. Um diálogo permanente de classes, mas tendo sempre a tutela estatal.

Além da sociologia, a influência do realismo jurídico norte-americano, é aposta segura de Vianna para enfatizar suas ideias de decisões que se afastem da lei e se firmem em razões sociais, afasta-se assim da ideia da exegese, para se fixar em uma interpretação menos restrita da lei, ideia que the será deveras importante para fixar a possibilidade da Justiça do Trabalho julgar os dissídios coletivos de acordo com os dados das partes em conflito.

E a Justiça do Trabalho quando concretizada teve como principal polêmica justamente seu poder normativo que, para os liberais, significava justamente uma invasão de poderes, daí o embate veemente que teve Vianna com o professor Waldemar Ferreira, representante dos interesses da FIESP (Federação das Indústrias de São Paulo). Vianna enfatizou que o novo Direito Público se norteava por novas visões, inclusive de novas fontes que não seriam só de poder legislativo, mas do poder executivo e judiciário também. E que isso não se norteava por ideias fascistas, mas era uma realidade prevista em todos os países, inclusive os mais democráticos, exemplo dos Estados Unidos da América, com suas agências regulamentadoras.

Ao tratar do sindicato de classes, Vianna vislumbra um papel educador das massas, que seria lento, mas fundamental para aprendizado de uma formação democrática de nossa gente. Vianna, não deixa de assumir o mito da outorga, ou seja, que antes da Revolução de 30, não havia sindicatos representativos, organizados e conquistadores de vários direitos. É com a chegada de Vargas e a implantação de seu estilo de Estado, que a classe trabalhadora toma consciência de si e é valorizada.

Sua ideia de sindicato único parte de possibilidade de ser construtor de regras para toda a categoria profissional e possibilitar o diálogo competente entre Estado e patrões. Destarte, acaba sendo criticado, pelas régias curtas que o Ministério do Trabalho, intervencionista, vai ter sobre os sindicatos. Contudo, tenta mais uma vez foge do modelo fascista, ao indicar que na Itália de então, era o Estado que escolhia a direção sindical.

Sem dúvidas, que a democratização do Brasil, via Constituição de 1988, tornou os sindicatos independentes e livres de intervenções estatais. Contudo, a ideia do sindicato único ainda prevalece, ao arrepio da Organização Internacional do Trabalho, que prega a pluralidade sindical. Mas, não é só. O chamado imposto sindical ainda permanece, resquício vivo da relação sindicato - Estado - imposições coletivas, já que todo empregado e empregadores, querendo ou não, são obrigados a colaborarem com seus sindicatos de classe. 
ISSN 1981-3694

(DOI): $10.5902 / 1981369423065$

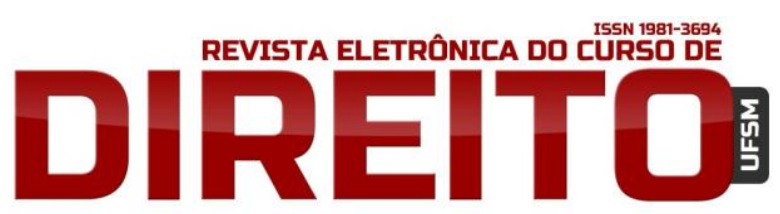

GRAND FINALE DA OBRA DE OLIVEIRA VIANNA EM NOSSA CONSTITUIÇÃO?

MARCELO TOLOMEI TEIXEIRA DAURY CESAR FABRIZ

Com efeito, ficou anotado que a engenharia de Oliveira Vianna, perpassou nossas constituições, certo ou errado, seu modelo, criticado por muito por ter engessado a classe trabalhadora enquanto sujeito histórico, ou seja, um modelo que acabou privilegiando o legislado ou as decisões normativas, em prol, de meios alternativos, fora do Estado, de resoluções de conflitos; e ainda por ter privilegiado sindicatos não representativos.

Merecedor de críticas? Com certeza, como toda a geração de trinta, simbolizava um modelo de estado autoritário e centralizador e ao nosso sentir castrador mesmo da luta sindical. Mas como a história tem suas contradições, quiçá um modelo mais liberto, ou seja, menos legislado e mais centrado na liberdade das negociações coletivas (exemplo do modelo norteamericano), nos sujeitasse hoje às ondas dos ventos liberais, que venta forte, em favor justamente de menos leis e mais liberdades para as negociações coletivas?

\section{REFERÊNCIAS}

BRESCIANI, Maria Stela Martins. O charme da ciência e a sedução da objetividade. 1. ed. São Paulo: UNESP, 2005.

DELGADO, Mauricio Godinho. Curso de Direito do Trabalho. 9. ed. São Paulo: LTR, 2012. MORAES FILHO, Evaristo. O Problema do Sindicato Único no Brasil. 2. ed. São Paulo: AlfaOmega, 1952.

VIANNA, Oliveira. Problemas de Direito Sindical. 1. ed. Rio de Janeiro: Max Limonad, 1943.

VIANNA, Oliveira. Instituições Políticas Brasileiras. 1. ed. Rio de Janeiro: EDUFF, 1987.

VIANNA, Oliveira. Problemas de Direito Corporativo. 1. ed. Rio de Janeiro: José Olympio, 1938.

VIEIRA, Evaldo Amaro. Oliveira Vianna e o Estado Corporativo. 1. ed. São Paulo: Grijalbo, 1976.

SUSSEKIND, Arnaldo. Curso de Direito do Trabalho. 1. ed. Rio de Janeiro: Renovar, 2002.

WARAT, Luiz Alberto. Introdução Geral ao Direito. 1. ed. Porto Alegre: Sergio Fabris, 1994.

Recebido em: 11/07/2016 / Revisões requeridas em: 08/06/2016 / Aprovado em: 22/09/2016 